\title{
Congenital primary adrenal insufficiency and selective aldosterone defects presenting as salt-wasting in infancy: a single center 10-year experience
}

\author{
Carla Bizzarri ${ }^{1 *}$ D, Nicole Olivini ${ }^{1}$, Stefania Pedicelli ${ }^{1}$, Romana Marini ${ }^{1}$, Germana Giannone ${ }^{2}$, Paola Cambiaso ${ }^{1}$
} and Marco Cappa ${ }^{1}$

\begin{abstract}
Background: Salt-wasting represents a relatively common cause of emergency admission in infants and may result in life-threatening complications. Neonatal kidneys show low glomerular filtration rate and immaturity of the distal nephron leading to reduced ability to concentrate urine.

Methods: A retrospective chart review was conducted for infants hospitalized in a single Institution from $1^{\text {st }}$ January 2006 to $31^{\text {st }}$ December 2015. The selection criterion was represented by the referral to the Endocrinology Unit for hyponatremia (serum sodium $<130 \mathrm{mEq} / \mathrm{L}$ ) of suspected endocrine origin at admission.

Results: Fifty-one infants were identified. In nine infants (17.6\%) hyponatremia was related to unrecognized chronic gastrointestinal or renal salt losses or reduced sodium intake. In 10 infants (19.6\%) hyponatremia was related to central nervous system diseases. In 19 patients (37.3\%) the final diagnosis was congenital adrenal hyperplasia (CAH). CAH was related to 21-hydroxylase deficiency in 18 patients, and to $3 \beta$-Hydroxysteroid dehydrogenase (3BHSD) deficiency in one patient. Thirteen patients ( $25.5 \%)$ were affected by different non-CAH salt-wasting forms of adrenal origin. Four familial cases of X-linked adrenal hypoplasia congenita due to NROB1 gene mutation were identified. Two unrelated girls showed aldosterone synthase deficiency due to mutation of the CYP11B2 gene. Two unrelated infants were affected by familial glucocorticoid deficiency due to MC2R gene mutations. One girl showed pseudohypoaldosteronism related to mutations of the SCNN1G gene encoding for the epithelial sodium channel. Transient pseudohypoaldosteronism was identified in two patients with renal malformations. In two infants the genetic aetiology was not identified.

Conclusions: Emergency management of infants presenting with salt wasting requires correction of water losses and treatment of electrolyte imbalances. Nevertheless, the differential diagnosis may be difficult in emergency settings, and sometimes hospitalized infants presenting with salt-wasting are immediately started on steroid therapy to avoid life-threatening complications, before the correct diagnosis is reached. Physicians involved in the management of infants with salt-wasting of suspected hormonal origin should remember that, whenever practicable, a blood sample for the essential hormonal investigations should be collected before starting steroid therapy, to guide the subsequent diagnostic procedures and in particular to address the analysis of candidate genes.
\end{abstract}

Keywords: Newborn, Infant, Salt-wasting, Sodium, Aldosterone, Adrenal insufficiency, Pseudohypoaldosteronism

\footnotetext{
* Correspondence: carla.bizzarri@opbg.net

'Unit of Endocrinology and Diabetes, Bambino Gesù Children's Hospital,

Piazza S. Onofrio 4, 00165 Rome, Italy

Full list of author information is available at the end of the article
} 


\section{Background}

Salt-wasting in newborns and infants represents a relatively common cause of emergency admission to hospital and may result in life-threatening complications. The kidneys are responsible of electrolyte homoeostasis, but neonatal kidneys show low glomerular filtration rate and immaturity of the distal nephron leading to reduced ability to concentrate urine. High extra-renal fluid losses often contribute to the increased occurrence of electrolyte disorders. Sodium is the main determinant of serum osmolality, and changes in sodium concentration can result in fluid shifts between intracellular and extracellular compartments. Water influx into the intracellular space swells cells, which can cause cerebral oedema and neurologic sequelae. Newborn and infants with hyponatremia (serum sodium concentration $<130 \mathrm{mEq} / \mathrm{L}$ ) may present with symptoms such as vomiting, irritability, hypotonia and seizures. In the outpatient setting, hyponatremia in infants is very uncommon, but can be caused by excess ingestion of free water and hypotonic fluids, such as overdiluted infant formula or plant milk, or by elevated salt loss with diarrhoea. Most cases of hyponatremia occur in hospitalized infants due to administration of hypotonic fluids, but also occur due to central nervous system pathology, lung disease, or postoperative complications. Severe hyponatremia with or without hyperkalemia, hypochloremia, metabolic acidosis and fasting hypoglycemia is life-threatening in newborns and infants and represents the most typical presentation mode of congenital primary adrenal insufficiency (PAI). The most common form of PAI is the congenital adrenal hyperplasia $(\mathrm{CAH})$ due to 21-hydroxylase deficiency, accounting for more than $75 \%$ of cases [1]. Xlinked adrenal hypoplasia congenital (AHC) and familial glucocorticoid deficiency (FGD) represent individually rare monogenic forms of PAI presenting with salt wasting during infancy [1, 2]. Aldosterone synthase deficiency (primary hypoaldosteronism) and aldosterone resistance (pseudohypoaldosteronism: PHA) can mimic clinical presentation of PAI, but glucocorticoid function is always normal in these disorders. However, in many neonatal cases not all the biochemical characteristic are evident at clinical presentation. Hyponatremia is found in $90 \%$ of patients with PAI, while hyperkalemia is seen in only $50 \%$ of patients [1]. Severe salt-wasting with hyponatremia is usually caused by selective mineralocorticoid deficiency, PHA and complete PAI (both glucocorticoid and mineralocorticoid deficiency), but also infants with isolated severe glucocorticoid deficiency (as patients with FGD) and preserved aldosterone secretion may show transient hyponatremia at presentation $[1,2]$.

\section{Pseudohypoaldosteronism (PHA)}

PHA is characterised by the renal tubular unresponsiveness to aldosterone and presents with hyponatremia, hyperkalaemia and metabolic acidosis with elevated plasma aldosterone and renin concentrations, but normal levels of ACTH and cortisol [3]. The differential diagnosis between congenital PAI and PHA may be challenging in an emergency setting and sometimes newborns and infants presenting with severe hyponatremia, hyperkalaemia, dehydration and metabolic acidosis are immediately started on mineralocorticoid and glucocorticoid therapy to avoid life-threatening complications, before the correct diagnosis is reached [4]. There are two types of primary PHA: PHA1 is characterized by failure to thrive, anorexia, nausea, and vomiting with hypotension, hyperkalemia, hyponatremia and acidosis, accompanied by high aldosterone levels; in contrast, PHA2 or type four renal tubular acidosis is due to the failure of the kidney to appropriately secrete potassium. Individuals with PHA2 show early-onset hypertension readily responsive to sodium restriction and thiazide diuretics, hyperkalemia, hyperchloremic acidosis, normal or low plasma renin activity, and subnormal plasma aldosterone level relative to the potassium level [5]. PHA1 is further categorized into two forms: autosomal recessive PHA1 due to a defect in the genes SCNN1A, $S C N N 1 B$ and SCNN1G encoding for the subunits $\alpha, \beta$ and $\gamma$ of the epithelial sodium channel $(\mathrm{ENaC})$, respectively; and autosomal dominant PHA1 due to mutations of the NR3C2 gene encoding for the mineralocorticoid receptor (MR) [5, 6]. Patients with autosomal recessive PHA1 present not only severe lifelong renal salt-wasting, but also salt-wasting from the lung, colon, sweat and salivary glands. As a result, these patients experience recurrent salt-wasting crises, pulmonary infections, congestion, coughing and wheezing, cholelithiasis, skin infections, and miliaria rubra. Initial presentation is usually severe dehydration early after birth, but sometimes autosomal recessive PHA1 has been diagnosed by neonatal cutaneous symptoms. These individuals are prone to life-threatening salt-losing crises throughout their lives. The pulmonary symptoms, clinically similar to those of cystic fibrosis, are due to poor absorption of liquids from airway surfaces and occur within weeks or months from birth. To note, there have been no described cases of neonatal respiratory distress in these patients. Instead, they experience recurrent lung infections such as bronchopneumonia by different pathogens as pseudomonas, pneumococcus, Staphylococcus aureus, Klebsiella, and Serratia [7]. Autosomal dominant PHA1 clinical expression is milder and confined to the kidney. Patients with autosomal dominant PHA1 generally present with renal salt wasting that subsides after early childhood. However, the presentation varies widely; it can occur in infancy with salt wasting, growth retardation, failure to thrive and occasionally death; or it can present in adulthood. It may be unmasked by an illness 
that impairs oral intake of fluids and salt or results in additional losses, such as viral gastroenteritis.

Secondary (transient) PHA is confined to the kidneys and has been described in infants and children with obstructive uropathy, pyelonephritis, tubulointerstitial nephritis, sickle cell nephropathy, systemic lupus erythematosus. Secondary PHA has been also related to drugs like non-steroidal anti-inflammatory drugs and potassium sparing diuretics $[3,6]$. It represents the result of a transient aldosterone resistance related to the kidney infection, in children with or without a predisposing renal malformation. The prognosis is good and the PHA usually reverts with the resolution of the infection.

\section{Primary selective hypoaldosteonism}

Primary selective hypoaldosteonism is a rare autosomal recessive disorder causing salt-wasting, accompanied by vomiting, failure to thrive, and dehydration during the first months of life. It is due to mutations in the CYP11B2 gene encoding for a cytochrome P450 enzyme, termed aldosterone synthase (CYP11B2, P450c11AS). This enzyme catalyzes the terminal steps in aldosterone biosynthesis comprising the conversion of 11-deoxycorticosterone to corticosterone, 18-hydroxycorticosterone, and finally aldosterone. The aldosterone synthase is expressed exclusively in the cells of the adrenal zona glomerulosa, limiting the synthesis of aldosterone to that zone [8].

\section{Familial glucocorticoid deficiency (FGD)}

FGD, also known as hereditary unresponsiveness to $\mathrm{ACTH}$, is characterized by lack of response to $\mathrm{ACTH}$ leading to adrenal insufficiency with subnormal glucocorticoid levels and remarkably elevated plasma ACTH levels. Aldosterone secretion is generally preserved, but hyponatremia at clinical presentation is common in infants [9]. Mutations in the ACTH receptor gene $(M C 2 R)$ account for $25 \%$ of FGD cases. Mutations in the melanocortin receptor accessory protein gene $(M R A P)$ account for $20 \%$, and mutations in the steroidogenic acute regulatory protein (STAR) gene account for $2.5 \%$ of cases. Recently, mutations in the mini-chromosome maintenance-deficient four homologue (MCM4) and nicotinamide nucleotide transhydrogenase (NNT) genes, involved in DNA replication and antioxidant defense, and mutations in TXNRD2 gene, encoding the mitochondrial selenoprotein thioredoxin reductase 2, have been also implicated [10-12].

\section{X-linked adrenal hypoplasia congenita (AHC)}

$\mathrm{X}$-linked adrenal hypoplasia congenita (AHC) is a potentially life-threatening condition characterized by primary adrenal insufficiency associated with hypogonadotropic hypogonadism Incidence was estimated to be about $1 / 12.500$ births. This genetic disorder is caused by mutations or deletions in $N R O B 1$ gene located on the short arm of chromosome X. NROB1 gene encodes for a nuclear receptor protein (DAX-1) which plays a key role in regulating the development of adrenal cortex, gonads, hypothalamus and pituitary gland. Salt-wasting crisis is often the first clinical manifestation of AHC occurring during the neonatal period, but timing and clinical presentations of the disease may be variable and characterized by non specific symptoms which can occur during childhood or adolescence [13].

\section{Autosomal adrenal hypoplasia congenita}

The first description of steroidogenic factor 1 (SF-1) protein abnormalities as a cause of human adrenal and testicular dysgenesis was published more than 15 years ago, and the spectrum of SF-1 associated conditions has expanded rapidly. SF-1 is encoded by the NR5A1 gene. Isolated PAI has been rarely associated with disruption of SF-1, whereas a range of reproductive phenotypes are more commonly seen, including $46 \mathrm{XY}$ disorders of sex development (DSD), with or without associated PAI, male infertility and premature ovarian failure. Most disease-associated variants are heterozygous, with rare homozygous changes described [13].

\section{Methods}

The study was conducted at Bambino Gesù Children's Hospital (Rome, Italy). A retrospective chart review was conducted for all patients with hyponatremia hospitalized during the first year of life, from $1^{\text {st }}$ January 2006 to $31^{\text {st }}$ December 2015. The selection criterion was represented by the referral to the Endocrinology Unit for hyponatremia (serum sodium $<130 \mathrm{mEq} / \mathrm{L}$ ) of suspected endocrine origin at admission. The diagnostic algorithm routinely used in our hospital to address the differential diagnosis of hyponatremia in infancy is summarized in Fig. 1. The following data were collected from the charts: clinical, biochemical and hormonal features at initial presentation, additional clinical features, and results of mutation analysis. The different candidate genes were sequenced to identify mutations, based on clinical characteristics and hormonal results of individual patients.

\section{Hormone assays}

Plasma ACTH and serum cortisol were measured by immunoluminometric assay and luminescence immunoassay (Nichols Institute, San Juan Capistrano, CA), respectively. Mean inter- and intrassay variability coefficients of variation were $<10 \%$ and $<4.8 \%$, respectively, for both methods. Commercial kits were used to estimate plasma renin (RIA, Sanofi-Pasteur), with mean intra- and interassay coefficients of variation 7, $9 \%$ and $10 \%$, respectively. 


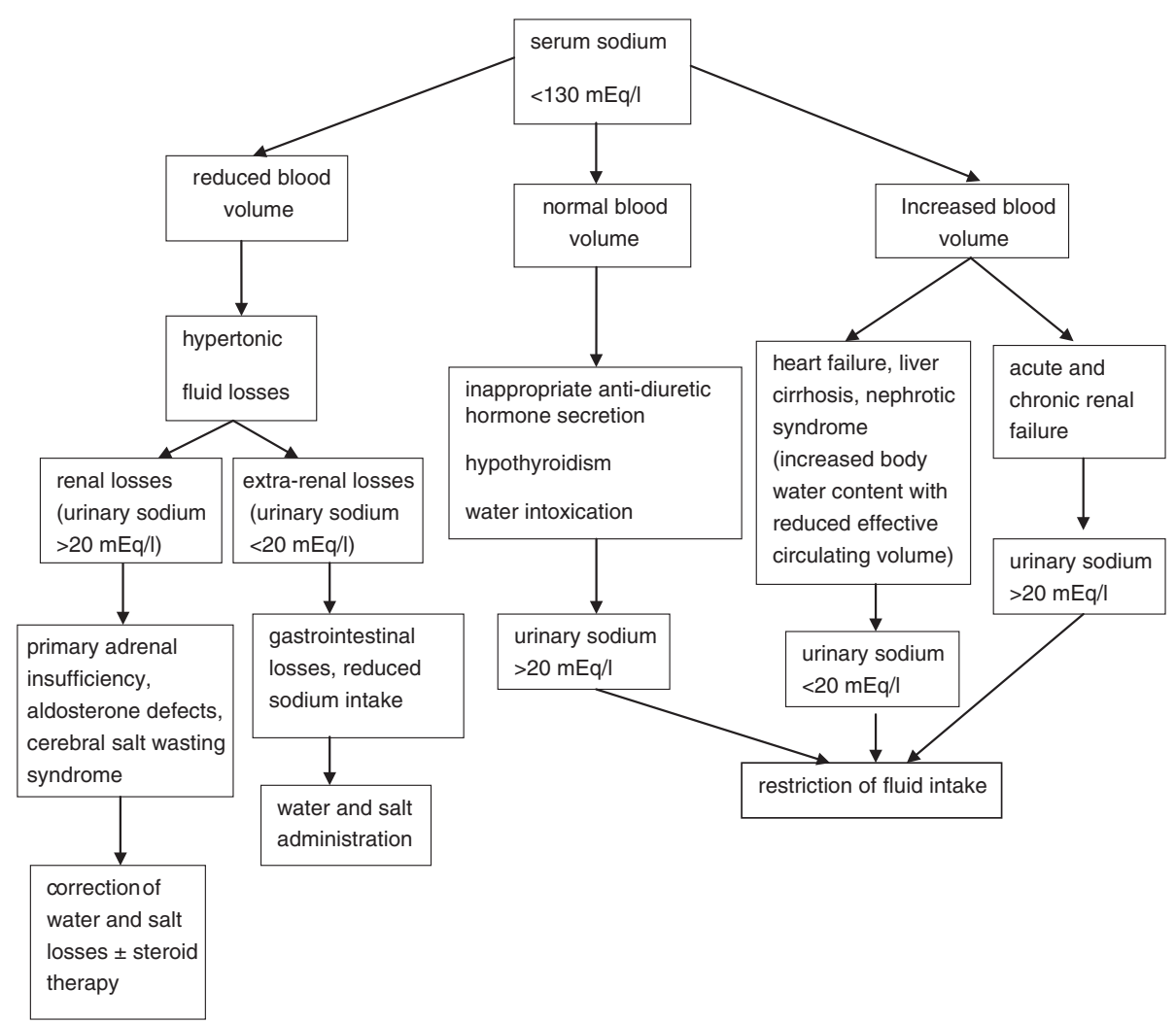

Fig. 1 Differential diagnosis and treatment of hyponatremia in infancy

\section{Results}

A total of 51 infants, admitted with significant hyponatremia $(<130 \mathrm{mEq} / \mathrm{l})$ and referred to the Endocrinology Unit were identified (Fig. 2).

At the end of the diagnostic work-up, hyponatremia was identified as related to chronic unrecognized salt losses or reduced sodium intake in nine infants (17.6\%): four infants with gastrointestinal diseases; three infants with renal diseases; two cases of bottle-feeding exclusively with over diluted rice milk not enriched with vitamins or minerals. In 10 infants (19.6\%) hyponatremia was related to central nervous system diseases, suggesting syndrome of inappropriate anti-diuretic hormone secretion and/or cerebral salt wasting syndrome. All these patients were excluded from the study.

In 19 patients $(37.3 \%)$ the final diagnosis was CAH. A defect of 21-hydroxylase (CYP21A2 gene) was identified in $18 \mathrm{CAH}$ patients (five females). One newborn male with perineal hypospadia and microphallus was found affected by $\mathrm{CAH}$ related to $3 \beta$-Hydroxysteroid dehydrogenase (3ßHSD) deficiency due to mutations in HSD3B2 gene. Despite all the five newborn girls with 21hydroxylase $\mathrm{CAH}$ showed severe virilization of the external genitalia (one girl with Prader stage 5; four girls with Prader stage 4), they had been discharged from the peripheral hospital where they were born with the alert about the possibility of a salt-wasting crisis and an appointment for an endocrinologic evaluation in the outpatient clinic, without undergoing any first-line hormonal investigations before discharge.

Thirteen patients (25.5\%) were found affected by non$\mathrm{CAH}$ salt-wasting forms of adrenal origin (Table 1). Four familial cases carrying the same NROB1 (DAX1) mutation were identified in two families (four boys born from two sisters). Two unrelated girls were found affected by aldosterone synthase deficiency due to mutation of the CYP11B2 gene. Two unrelated children (one male) showed FGD due to $M C 2 R$ mutations. One girl showed autosomal recessive PHA1 related to compound heterozygosity for two variants in intron eight of the SCNN1G gene (c.1294+5G > A e c.1295-10 T > A). In this case bioinformatics analysis showed that the first variation abolished the 5 ' splice site and was probably pathogenic, while the second variation was predicted to abolish the 3 ' splice site and to introduce a cryptic splice site of unknown significance. Two cases of transient PHA were identified, both of them were related to urinary infections in patients with renal malformations. Finally, in two infants (one male) with a clinical and hormonal diagnosis of PAI, the final genetic aetiology was not 


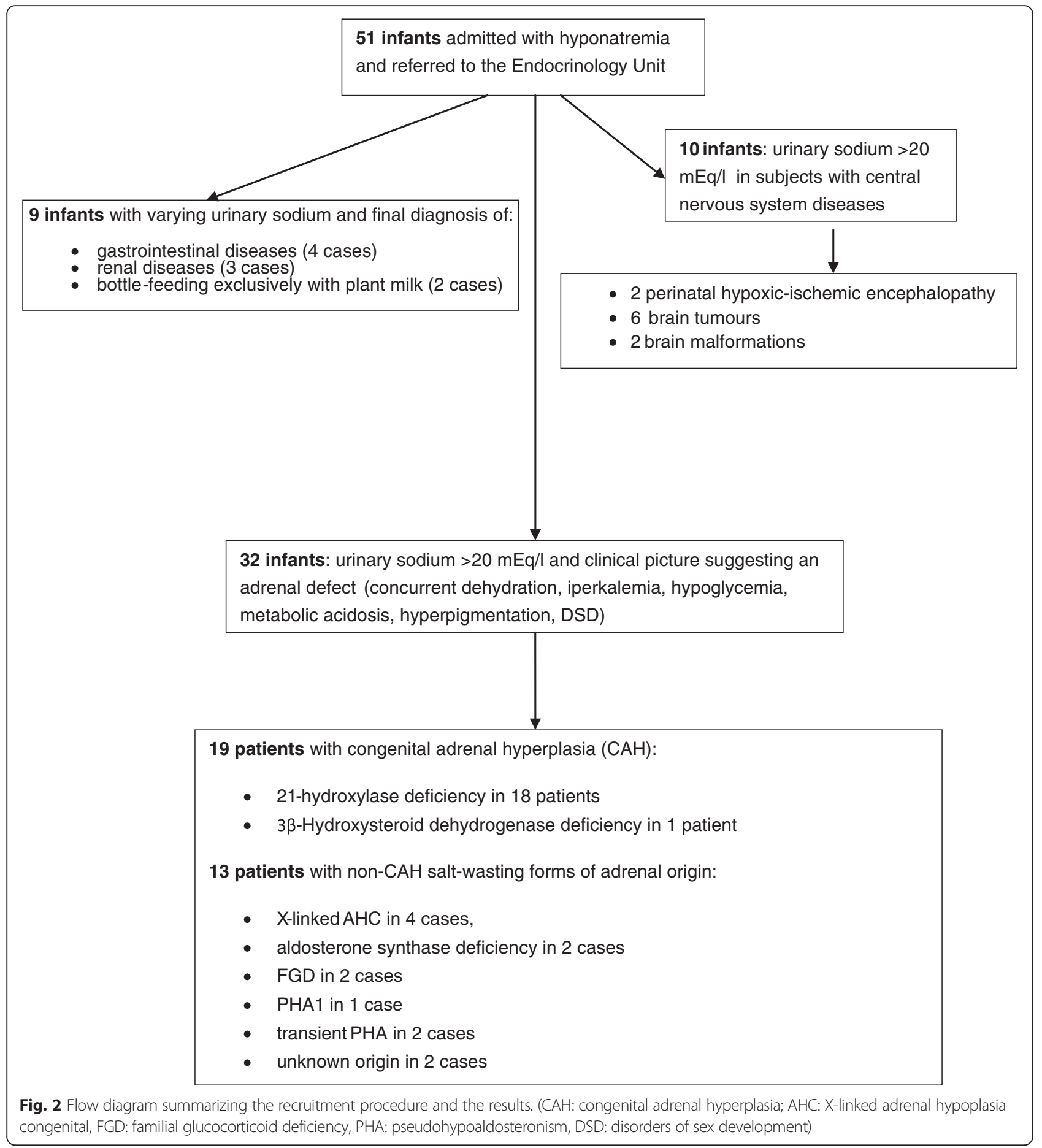

identified. Based on individual clinical details, $C Y P 21 A 2$, CYP11B1, HSD3B2, CYP17A1, POR, NROB1 (DAX1) and NR5A1 (SF1) genes were sequenced in both these children. Very long chain fatty acids (VLCFA) were measured in both patients, and were in the normal range. In the boy, Smith-Lemli-Opitz syndrome was also excluded by the study of DHCR7 gene, encoding for 7-dehydrocholesterol reductase.

\section{Discussion}

PAI is uncommon in the Western population; 90 to 140 subjects per 1 million people have been estimated to be affected [14]. In contrast to the predominance of autoimmune adrenal insufficiency in adults, most cases of PAI in childhood show an inherited, monogenic origin [15]. Genetic causes of paediatric PAI can be classified into four major groups according to the underlying 
Table 1 Characteristics of infants with non-CAH salt-wasting forms of adrenal origin

\begin{tabular}{|c|c|c|c|c|c|c|c|c|c|c|c|c|c|c|c|c|c|c|}
\hline & $\begin{array}{l}\text { Age at } \\
\text { onset } \\
\text { (days) }\end{array}$ & Sex & Ethnicity & Ancestry & $\begin{array}{l}\text { Clinical } \\
\text { presentation }\end{array}$ & $\begin{array}{l}\text { Additional } \\
\text { clinical } \\
\text { features }\end{array}$ & $\mathrm{pH}$ & $\begin{array}{l}\text { Nammol/ } \\
\text { L(135-145) }\end{array}$ & $\begin{array}{l}\mathrm{K} \text { mmol/ } \\
\mathrm{L}(3.5-5.5)\end{array}$ & $\begin{array}{l}\text { Cl mmol/ } \\
\text { L(95-110) }\end{array}$ & $\begin{array}{l}\text { Glucose } \\
\mathrm{mg} / \mathrm{dl} \\
(50-110)\end{array}$ & $\begin{array}{l}\text { Blood } \\
\text { pressure } \\
\mathrm{mmHg}\end{array}$ & $\begin{array}{l}\mathrm{ACTH} \\
\mathrm{pg} / \mathrm{ml} \\
(5-55)\end{array}$ & $\begin{array}{l}\text { Cortisol } \\
\mathrm{mcg} / \mathrm{dl} \\
(5-20)\end{array}$ & $\begin{array}{l}\text { Aldosterone } \\
\mathrm{pg} / \mathrm{ml} \text { (50-900) }\end{array}$ & $\begin{array}{l}\text { Renin } \\
\mathrm{pg} / \mathrm{ml} \\
(5-270)\end{array}$ & Gene & Mutation \\
\hline 1 & 21 & M & Caucasian & Romanian & $\begin{array}{l}\text { Salt wasting } \\
\text { crisis, fever, } \\
\text { fatigue, poor } \\
\text { feeding }\end{array}$ & NR & & 130 & 5.74 & 92 & 89 & $72 / 36$ & 286 & 5.6 & 165 & 784 & $N R O B 1$ & P353LfsX387 \\
\hline 2 & 21 & M & Caucasian & Romanian & $\begin{array}{l}\text { Poor feeding, } \\
\text { dehydration, } \\
\text { hyperpigmentation }\end{array}$ & NR & & 127.2 & 5.9 & 95 & 48 & $79 / 40$ & 356 & 6.5 & 56 & 668 & $N R O B 1$ & P353LfSX387 \\
\hline 3 & 3 & M & Caucasian & Romanian & Poor feeding & NR & & 133 & 5.4 & 99 & 62 & & 184 & 4.8 & 54 & 452 & $N R O B 1$ & P353LfSX387 \\
\hline 4 & 8 & M & Caucasian & Romanian & $\begin{array}{l}\text { Poor feeding, } \\
\text { recurrent vomiting }\end{array}$ & NR & 7.27 & 127 & 6.91 & 99 & 66 & & 176 & 14 & & 528 & NROB1 & P353LfSX387 \\
\hline 5 & 18 & & Caucasian & Italian & $\begin{array}{l}\text { Dehydration, } \\
\text { failure to thrive, } \\
\text { poor feeding }\end{array}$ & NR & 7.12 & 127 & 9.53 & 93 & 57 & $65 / 38$ & 59.3 & 22.4 & $>800$ & 639 & SCNN1G & $\begin{array}{l}\text { c.1294+5G>A, } \\
\text { c.1295-10T>A }\end{array}$ \\
\hline 6 & 60 & $\mathrm{~F}$ & Caucasian & Italian & $\begin{array}{l}\text { failure to thrive, } \\
\text { recurrent vomiting }\end{array}$ & NR & 7.43 & 124 & 6.1 & 94 & 68 & $73 / 40$ & 19.1 & 14.9 & 98 & 826 & CYP11B2 & $\begin{array}{l}\text { Q170X, E198D, } \\
\text { V386A }\end{array}$ \\
\hline 7 & 24 & $\mathrm{~F}$ & Caucasian & Italian & $\begin{array}{l}\text { failure to thrive, } \\
\text { recurrent vomiting }\end{array}$ & NR & 7.38 & 120 & 6.72 & 99 & 69 & $72 / 35$ & 15.8 & 5.7 & 255 & 1250 & CYP11B2 & $\begin{array}{l}\text { p.T185I, } \\
\text { p.E198D, } \\
\text { p.V386A }\end{array}$ \\
\hline 8 & 1 & M & Caucasian & Italian & $\begin{array}{l}\text { Hypoglycemia, } \\
\text { respiratory distress, } \\
\text { hyperpigmentation }\end{array}$ & $\begin{array}{l}\text { cholestatic } \\
\text { jaundice }\end{array}$ & 7.27 & 126 & 3.77 & 97 & 50 & $70 / 35$ & $>1250$ & $<0.2$ & 224 & 107 & $M C 2 R$ & T159K, A233D \\
\hline 9 & 1 & $\mathrm{~F}$ & Caucasian & Italian & $\begin{array}{l}\text { Hypoglycemia, } \\
\text { poor feeding, } \\
\text { recurrent vomiting, } \\
\text { hyperpigmentaiton }\end{array}$ & $\begin{array}{l}\text { cholestatic } \\
\text { jaundice }\end{array}$ & 7.29 & 128 & 3.92 & 98 & 24 & $69 / 34$ & 1248 & 0.49 & 181 & 181 & $M C 2 R$ & T159K \\
\hline 10 & 28 & M & Caucasian & Albanian & $\begin{array}{l}\text { poor feeding, } \\
\text { recurrent } \\
\text { vomiting, fever }\end{array}$ & $\begin{array}{l}\text { Urinary sepsis, } \\
\text { right kidney } \\
\text { hypoplasia }\end{array}$ & 7.30 & 129 & 7.56 & 97 & 52 & $80 / 40$ & 23 & 13.1 & 933 & 456 & $\begin{array}{l}\text { Transient } \\
\text { PHA }\end{array}$ & \\
\hline 11 & 90 & M & Caucasian & Romanian & $\begin{array}{l}\text { poor feeding, } \\
\text { hypotonia, recurrent } \\
\text { vomiting, fever }\end{array}$ & $\begin{array}{l}\text { Urinary sepsis, } \\
\text { right renal } \\
\text { pelvis } \\
\text { distension }\end{array}$ & 7.31 & 122 & 7.34 & 96 & 53 & $80 / 43$ & 43 & 12 & 989 & 563 & $\begin{array}{l}\text { Transient } \\
\text { PHA }\end{array}$ & \\
\hline 12 & 180 & $\mathrm{~F}$ & Caucasian & Italian & $\begin{array}{l}\text { poor feeding, } \\
\text { recurrent vomiting, } \\
\text { diarrhea }\end{array}$ & $\begin{array}{l}\text { Intrauterine } \\
\text { growth } \\
\text { retardation }\end{array}$ & 7.22 & 110 & 6.3 & 74 & 44 & $88 / 44$ & $>1250$ & 2.91 & 155 & 677 & unknown & \\
\hline 13 & 15 & M & Caucasian & Italian & $\begin{array}{l}\text { Dehydration, failure } \\
\text { to thrive, recurrent } \\
\text { vomiting, } \\
\text { hyperpigmentation }\end{array}$ & $\begin{array}{l}46 \text { XY,DSD, } \\
\text { dysmorphic } \\
\text { features, } \\
\text { retinopathy, } \\
\text { developmental } \\
\text { delay }\end{array}$ & 7.23 & 122 & 6.9 & 89 & 43 & & $>1250$ & 2.3 & 98 & 478 & unknown & \\
\hline
\end{tabular}


pathogenesis: impaired steroidogenesis, adrenal hypoplasia, familial glucocorticoid deficiency (FGD), and adrenal destruction. Congenital adrenal hyperplasia (CYP21A2, CYP11B1, HSD3B2, CYP17A1, POR defects) constitutes the largest subgroup of impaired steroidogenesis and represents the most common cause of PAI in children [15]. In contrast, different individually rare causes of PAI as X-linked AHC (NROB1/DAX-1), autosomal adrenal hypoplasia (NR5A1/SF-1), congenital lipoid adrenal hyperplasia (CYP11A1, STAR gene defects), FGD, adrenal autoimmune destruction and adrenoleukodystrophy $(A B C D 1)$ are now well established $[15,16]$.

Perry et al. [16] reported their 20-year experience with PAI in 103 children $<18$ years old in Montreal, Canada. An aetiology of PAI was identified in $94 \%$ of cases: $72 \%$ were affected by $\mathrm{CAH}, 13 \%$ had autoimmune adrenal insufficiency, and the remaining $15 \%$ had adrenoleukodystrophy, rare syndromes (Wolman, Zellweger, etc.), or unexplained adrenal insufficiency.

In a study performed in Melbourne, Australia [17] in which only non-CAH cases were reported, there were five cases each of autoimmune adrenal insufficiency, adrenoleukodystrophy, and X-linked AHC and one case of the IMAGE syndrome (characterized by intrauterine growth retardation, metaphyseal dysplasia, adrenal hypoplasia congenita, and genital anomalies).

A recent study performed in a population from the island portion of Newfoundland and Labrador, Canada, reported mutation analysis of candidate genes in 11 patients with PAI. The aetiology of PAI was identified in nine patients. One had a homozygous $M C 2 R$ mutation associated with FGD. Two had the same homozygous mutation in the autoimmune regulator (AIRE) gene, which is associated with type 1 autoimmune polyglandular syndrome. One patient had a heterozygous change in AIRE gene of undetermined significance. Five were homozygous for the same mutation of the gene encoding the steroidogenic acute regulatory (STAR) protein causing non-classic lipoid CAH. In the remaining two patients, no clear aetiology was identified. In this study, the high proportion of patients with non-classic lipoid $\mathrm{CAH}$ strongly suggests a founder effect in a relatively isolated population [18].

It is now emerging that a considerable overlap exists in the clinical and biochemical presentation of the different genetic forms of PAI. FGD can present with salt loss suggestive of adrenal hypoplasia, and alterations in STAR and CYP11A1 resulting in partial loss of protein function may have a predominant FGD-like phenotype, with glucocorticoid deficiency without genital abnormalities in 46,XY newborns [18, 19].

To our knowledge, this is the first study focusing on salt-wasting and hyponatremia as clinical presentation of congenital adrenal defects in infancy. Our Institution is the main Children's Hospital of Lazio region, in the central Italy. In Lazio region, the neonatal screening for $\mathrm{CAH}$ is not performed. Our Institution does not include a department of Obstetrics and sick newborn babies are referred to us from peripheral birth hospitals. In female babies, $\mathrm{CAH}$ is more easily suspected due to the presence of genital abnormalities. Female babies are usually referred immediately after birth, before the onset of an overt electrolyte imbalance. This probably explains why in our population, selected on the basis of hyponatremia at the first observation, the number of females with $\mathrm{CAH}$ was significantly lower than the number of males. Nevertheless, all the five girls with CAH showed hyponatremia at the first outpatient consultation, without overt dehydration and salt wasting, and were admitted to confirm CAH diagnosis and start treatment. As expected, the number of patients affected by the other forms of salt wasting of adrenal origin was low, and a genetic cause was not found in two patients. Surprisingly, in our study the proportion of patients with primary selective hypoaldosteronism (two unrelated cases) was relatively high, considering that the estimated incidence of this defect is probably $<1 / 1,000,000 /$ year $[20,21]$. One case of aldosterone synthase (CYP11B2) deficiency and the case affected by $3 \beta$-Hydroxysteroid dehydrogenase (3ßHSD) deficiency were previously described [22, 23].

Severe salt-wasting with hyponatremia is caused by mineralocorticoid deficiency or complete adrenal insufficiency (both glucocorticoid and mineralocorticoid deficiency), but also infants with isolated severe glucocorticoid deficiency and preserved aldosterone secretion may present with mild hyponatremia, which is usually transient. Interestingly, both patients with severe FGD due to $M C 2 R$ mutations showed mild hyponatremia at onset, without dehydration and overt salt-wasting. It has been described that in severe glucocorticoid deficiency plasma antidiuretic hormone $(\mathrm{ADH})$ levels are elevated, because of the decreased effective circulating blood volume, impairing the ability to dilute the urine. Cortisol acts as a negative feedback mechanism on both $\mathrm{CRH}$ and $\mathrm{ADH}$ secretion. ADH is cosecreted with CRF by the paraventricular nuclei. If cortisol levels are chronically low, the amount of ADH can continue to increase causing dilutional hyponatremia [2].

\section{Conclusions}

Emergency management of newborns infants presenting with dehydration and salt wasting requires correction of water losses and treatment of electrolyte imbalances. Nevertheless, the differential diagnosis between congenital PAI and PHA may be difficult in emergency settings, and sometimes hospitalized infants presenting with saltwasting and metabolic acidosis are immediately started on mineralocorticoid and glucocorticoid therapy to avoid 
life-threatening complications, before the correct diagnosis is reached $[4,24,25]$. Steroid therapy (with both glucocorticoids and mineralocorticoids) is life-saving in PAI, while it is not effective in restoring salt and water balance in PHA. After correction of dehydration, children with aldosterone synthase deficiency require mineralocorticoid therapy only, even if stress doses of glucocorticoids administered intravenously are able to restore the electrolyte balance because cortisol is able to bind the MR [20, 21]. Physicians involved in the management of infants with salt wasting of suspected endocrine origin should remember that, whenever practicable, a blood sample for the essential hormonal investigations $(\mathrm{ACTH}$, cortisol, $17 \mathrm{OH}$ progesterone, androstenedione, renin, aldosterone) should be collected before starting steroid therapy, to guide the subsequent diagnostic procedures and in particular to address the analysis of candidate genes.

\section{Abbreviations \\ $\mathrm{ADH}$, anti-diuretic hormone; $\mathrm{AHC}$, adrenal hypoplasia congenita; $\mathrm{CAH}$, congenital adrenal hyperplasia; DSD, disorders of sex development; ENaC, epithelial sodium channel; FGD, familial glucocorticoid deficiency; MR, mineralocorticoid receptor; PAl, primary adrenal insufficiency; PHA, pseudohypoaldosteronism}

\section{Acknowledgements}

We greatly appreciate the secretarial assistance of Mrs. Luciana Luciani of the Unit of Endocrinology and Diabetes, "Bambino Gesù" Children's Hospital Rome, Italy.

\section{Funding}

Institutional funds were used for this research.

\section{Availability of data and materials}

The dataset supporting the conclusions of this article is included within the article.

\section{Authors' contributions}

CB conceived the study, participated in its design and coordination and drafted the manuscript. NO and SP collected the data and contributed to draft the manuscript. RM and PC followed clinically the patients an coordinated the analysis of candidate genes. GG carried out the immunoassays. MC conceived the study and carried out the correction of the manuscript. All authors read and approved the final manuscript.

\section{Competing interests}

The authors declare that they have no competing interests.

\section{Consent for publication}

Consent to publish was obtained from all patients' parents.

\section{Ethics approval and consent to participate}

The study was approved by the Institutional Ethics and Research Committee. The informed consent was obtained from parents, after full explanation of the purpose and nature of all procedures used.

\section{Author details}

'Unit of Endocrinology and Diabetes, Bambino Gesù Children's Hospital, Piazza S. Onofrio 4, 00165 Rome, Italy. Department of Chemistry, Bambino Gesù Children's Hospital, Rome, Italy.

Received: 22 May 2016 Accepted: 24 July 2016

Published online: 02 August 2016

\section{References}

1. Hsieh S, White PC. Presentation of primary adrenal insufficiency in childhood. J Clin Endocrinol Metab. 2011;96(6):E925-8.

2. Lin L, Hindmarsh $P$, Metherell $L$, Alzyoud M, Al-Ali M, Brain C, et al. Severe loss-of-function mutations in the adrenocorticotropin receptor (ACTHR, MC2R) can be found in patients diagnosed with salt-losing adrenal hypoplasia. Clin Endocrinol (Oxf). 2007;66(2):205-10.

3. Geller DS. Mineralocorticoid resistance. Clin Endocrinol (Oxf). 2005;62(5):513-20.

4. Sopfe J, Simmons JH. Failure to thrive, hyponatremia, and hyperkalemia in a neonate. Pediatr Ann. 2013;42(5):74-9.

5. Furgeson SB, Linas S. Mechanisms of type I and type II pseudohypoaldosteronism. J Am Soc Nephrol. 2012;21(11):1842-5.

6. Riepe FG. Clinical and molecular features of type 1 pseudohypoaldosteronism. Horm Res. 2009;72(1):1-9.

7. Marthinsen L, Kornfalt R, Aili M, Anderrson D, Westgren U, Schaedel C. Recurrent Pseudonomas bronchopneumonia and other symptoms as in cystic fibrosis in a child with type I pseudohypoaldosteronism. Acta Pediatrica. 1998;87(4):472-4.

8. White PC. Aldosterone synthase deficiency and related disorders. Mol Cell Endocrinol. 2004;217(1-2):81-7.

9. Meimaridou E, Hughes CR, Kowalczyk J, Chan L, Clark A, Metherell L. ACTH resistance: genes and mechanisms. Endocr Dev. 2013;24:57-66.

10. Meimaridou E, Hughes C, Kowalczyk J, Gausti L, Chapple J, King P. Familial glucocorticoid deficiency: new genes and mechanisms. Mol Cell Endocrinol. 2013;371(1-2):195-200.

11. Meimaridou E, Kowalczyk J, Guasti L, Hughes C, Wagner F, Frommolt P, et al. Mutations in NNT encoding nicotinamide nucleotide transhydrogenase cause familial glucocorticoid deficiency. Nat Genet. 2012;44(7):740-2.

12. Prasad R, Chan L, Hughes C, Kaski J, Kowalczyk J, Savage M, et al. Thioredoxin reductase 2 (TXNRDd2) mutation associated with familial glucocorticoid deficiency (FGD). J Clin Endocrinol Metab. 2014;99(8):E1556-63.

13. Suntharalingham JP, Buonocore F, Duncan AJ, Achermann JC. DAX-1 (NROB1) and steroidogenic factor-1 (SF-1, NR5A1) in human disease. Best Pract Res Clin Endocrinol Metab. 2015;29(4):607-19.

14. Arlt W, Allollo B. Adrenal insufficiency. Lancet. 2003;361(9372):1881-93.

15. Miller WL, Flück CE. Adrenal cortex and its disorders. In: Sperling MA, editor. Pediatric Endocrinology. 4th ed. Philadelphia: Saunders; 2014

16. Perry R, Kecha O, Paquette J, Huot C, Van Vliet G, Deal C. Primary adrenal insufficiency in children: twenty years experience at the Sainte-Justine Hospital, Montreal. J Clin Endocrinol Metab. 2005;90(6):3243-50.

17. Simm PJ, McDonnell CM, Zacharin MR. Primary adrenal insufficiency in childhood and adolescence: advances in diagnosis and management. J Paediatr Child Health. 2004;40(11):596-9.

18. Tsai SL, Green J, Metherell LA, Curtis F, Fernandez B, Healey A, et al. Primary adrenocortical insufficiency case series: genetic etiologies more common than expected. Horm Res Paediatr. 2016;85(1):35-42.

19. Malikova J, Flück CE. Novel insight into etiology, diagnosis and management of primary adrenal insufficiency. Horm Res Paediatr. 2014;82(3):145-57.

20. Miller WL, Auchus RJ. The molecular biology, biochemistry, and physiology of human steroidogenesis and its disorders. Endocr Rev. 2011:32(1):81-151.

21. Root AW. Disorders of aldosterone synthesis, secretion, and cellular function. Curr Opin Pediatr. 2014;26(4):480-6.

22. Taranta A, Bizzarri C, Masotti A, Sciré G, Pampanini V, Cappa M. A case of primary selective hypoaldosteronism carrying three mutations in the aldosterone synthase (Cyp11b2) gene. Gene. 2012;500(1):22-7.

23. Bizzarri C, Massimi A, Federici L, Cualbu A, Loche S, Bellincampi L, et al. A New Homozygous Frameshift Mutation in the HSD3B2 Gene in an Apparently Nonconsanguineous Italian Family. Horm Res Paediatr. 2016. [Epub ahead of print].

24. Attia NA, Marzouk YI. Pseudohypoaldosteronism in a Neonate Presenting as life-threatening hyperkalemia. Case Rep Endocrinol. 2016;2016:6384697.

25. Clayton PE, Miller WL, Oberfield SE, Ritzén EM, Sippell WG, Speiser PW, ESPE/LWPES CAH Working Group. Consensus statement on 21-hydroxylase deficiency from the European Society for Paediatric Endocrinology and the Lawson Wilkins Pediatric Endocrine Society. Horm Res. 2002;58(4):188-95. 